\title{
Transforming growth factor- $\beta$-induced miR-143 expression in regulation of non-small cell lung cancer cell viability and invasion capacity in vitro and in vivo
}

\author{
TIANLI CHENG, CHENGPING HU, HUAPING YANG, LIMING CAO and JIAN AN
}

Department of Respiratory Medicine, Xiangya Hospital, Central South University, Changsha 410008, P.R. China

Received June 26, 2014; Accepted August 12, 2014

DOI: $10.3892 /$ ijo.2014.2623

\begin{abstract}
Altered expression of miRNAs contributes to development and progression of non-small cell lung cancer (NSCLC), while transforming growth factor- $\beta$ (TGF- $\beta$ ) promotes NSCLC cell epithelial-mesenchymal transition. This study aimed to investigate the effects of TGF- $\beta$-induced miR-143 expression in regulation of NSCLC cell viability, invasion capacity in vitro, and xenograft formation and growth in nude mice. NSCLC A549 cells treated with TGF- $\beta$ were subjected to miRNA microarray analysis and miR-143 was selected for further study of tumor cell viability, wound healing, invasion capacity in vitro, and tumor growth in nude mice. TGF- $\beta$ treatment upregulated expression of 16 miRNAs and downregulated expression of 42 miRNAs in A549 cells. qRT-PCR and in situ hybridization data showed that miR-143 was significantly downregulated in 24 NSCLC and lymph node metastatic tumor tissues, but upregulated by TGF- $\beta$ treatment in A549 cells. In vitro experiments showed that miR-143 expression could significantly suppress NSCLC cell viability and invasion capacity, and nude mouse experiments confirmed the in vitro data. Bioinformatic data predicted that Smad3, CD44 and K-Ras were the targeting genes of miR-143. TGF- $\beta$ induced miR-143 expression was associated with suppressed expression of Smad3, CD44, and K-Ras. This study sheds light on the role of TGF- $\beta$ in upregulation of miR-143 and the role of miR-143 in NSCLC progression, indicating that the target of miR-143 expression could be further studied as a novel therapeutic strategy for future control of NSCLC.
\end{abstract}

\section{Introduction}

Lung cancer is the leading cause of cancer deaths in the world and cancer metastasis is the major cause of death in lung cancer patients (1). Non-small cell lung cancer (NSCLC) accounts for $\sim 85 \%$ of all lung cancer cases, and to date, its overall 5-year

Correspondence to: Professor Chengping $\mathrm{Hu}$, Department of Respiratory Medicine, Xiangya Hospital, Central South University, Changsha 410008, P.R. China

E-mail: huchengp28@126.com

Key words: TGF- $\beta$, NSCLC, miRNA, miR-143 survival rate is $\sim 15 \%$ (2). Lung cancer is expected to remain a major health hurdle for the next $40-50$ years $(3,4)$. Therefore, development of effective therapies for NSCLC is urgently needed.

miRNAs are small non-coding RNAs that can degrade target mRNA and suppress protein translation $(5,6)$. miRNAs could post-transcriptionally regulate gene expression and therefore, modulate cell function and homeostasis and act as tumor suppressor genes or oncogenes (7). On average, each miRNA is estimated to be able to regulate several hundred protein-coding genes, and $\sim 60 \%$ of proteins in cells is thought to be regulated by miRNAs $(8,9)$. Thus, changes in miRNA expression pattern are linked to profound effects on cell phenotypes, and miRNAs have an emerging role in diverse physiological and pathological processes (10). In this regard, altered miRNA expression will lead to human carcinogenesis and cancer progression. For example, miR-143 targets K-Ras, Bcl-2, and other genes to regulate tumor cell proliferation and invasion capacity $(11,12)$. Furthermore, transforming growth factor- $\beta$ (TGF- $\beta$ ) acts as a tumor suppressor in normal tissues, but the suppressive effects are lost during early carcinogenesis of advanced tumors.

TGF- $\beta$-induced epithelial-to-mesenchymal transition (EMT) contributes to human carcinogenesis (13-15). EMT usually occurs during critical phases of embryonic development (such as mesoderm and neural tube formation), wound healing, or initiation of metastasis during cancer progression. During EMT, epithelial cells lose polarity and cell-cell adhesion, and acquire migration and invasion properties of mesenchymal cells (13-15). At the gene level, various genes participate in EMT; for example, TGF- $\beta$, a protein that controls proliferation, cellular differentiation, and other functions in most human cells, can promote NSCLC cell EMT (16-18). However, it is unknown how TGF- $\beta$ regulates miRNA expression or EMT to regulate cell apoptosis and tumor progression and whether there is a relationship between miR-143 and TGF- $\beta$, previous studies indeed show that miR-143 can regulate EMT and tumor cell growth and apoptosis (19-21). For example, Davis et al showed that TGF- $\beta$ interacts with myocardin (Myocd) or Myocd-related transcription factors to induce pri-miR-143/145 expression and in turn, miR-143/145 downregulates KLF4 transcription to control vascular smooth muscle cells contractile phenotypes and mediate induction of contractile genes (22). Thus, in this study, we investigated the effects of TGF- $\beta$ induction on miR-143 expression and then assessed the effects 
of miR-143 expression or knockdown on the regulation of NSCLC cell viability and invasion capacity in vitro, along with xenograft formation and growth in nude mice.

\section{Materials and methods}

Cell line and culture. Human NSCLC A549 cell line was purchased from American Type Culture Collection (ATCC, Manassas, VA, USA) and cultured with RPMI-1640 medium supplemented with $10 \%(\mathrm{v} / \mathrm{v})$ heat-inactivated fetal bovine serum (Hyclone Laboratories, Inc., Logan, UT, USA) in an atmosphere of $95 \%$ air and $5 \% \mathrm{CO}_{2}$ at $37^{\circ} \mathrm{C}$. Recombinant human TGF- $\beta$ was purchased from R\&D Systems (MN, USA) and used to treat the cultured cells $(400 \mathrm{pM})$. Cells were cultured under starvation conditions ( $0.2 \%$ FBS) overnight $(\sim 16 \mathrm{~h})$ prior to growth factor stimulation as described previously (23).

miRNA microarray analysis. Total cellular RNA was isolated from the cultured cells using TRIzol reagent (Invitrogen, Carlsbad, CA, USA) and purified using an RNA easy mini kit (Qiagen, Frankfurt, Germany) according to the manufacturer's instructions. The isolated RNA samples were quantified using a Nanodrop instrument (Thermo Fisher, Wilmington, DE, USA) and then labeled with the miRCURY ${ }^{\mathrm{TM}} \mathrm{Hy} 3^{\mathrm{TM}} / \mathrm{Hy} 5^{\mathrm{TM}}$ Power labeling kit (Qiagen). After that, the labeled RNA samples were used as probes to hybridize onto the miRCURY ${ }^{\mathrm{TM}}$ LNA Array (v.2.0, Affymetrix) in a hybridization station (Capitalbio, Beijing, China) according to a previous study (24). The array sections were scanned using the Axon GenePix 4000B microarray scanner (Capitalbio) and the data were read and analyzed using GenePix pro V6.0 software (Capitalbio) for the raw intensity of the images.

The threshold value used to screen up- and downregulated miRNAs was the degree of change ( $\geq 1.5$ - and $\leq 0.75$-fold; $\mathrm{p} \leq 0.05$ ). A heat map diagram was used to display data for two-way hierarchical clustering of genes and samples.

Quantitative reverse transcription-polymerase chain reaction ( $q R T-P C R)$. Total cellular RNA was isolated using a $\mathrm{TRIzol}^{\circledR}$ reagent (Invitrogen) from cultured cells. RT reactions were performed using the iScript cDNA synthesis kit (Bio-Rad, Hercules, CA, USA) and qPCR was performed in a Bio-Rad IQTM5 Multicolor Real-Time PCR detection system (Bio-Rad). The qPCR cycle was set an initial $98^{\circ} \mathrm{C}$ for $2 \mathrm{~min}, 40$ cycles of $95^{\circ} \mathrm{C}$ for $15 \mathrm{sec}, 60^{\circ} \mathrm{C}$ for $30 \mathrm{sec}$, and a final melt-curve analysis $\left(60-95^{\circ} \mathrm{C}\right)$ was included. The standard curve was produced with slopes at $\sim 3.32$ ( $\sim 100 \%$ efficiency); miRNA PCR quantification used the $2^{\Delta \Delta c t}$ method against the U6 for normalization. mRNA PCR quantification used the $2^{\Delta \Delta c t}$ method against the $\beta$-actin for normalization. The data are representative of the means of three experiments. Primers for qPCR were designed to detect miRNA based on the miRNA sequences provided by the Sanger Center miRNA Registry, were and synthesized and purified by Shanghai Gene-Pharma Co. (Shanghai, China). Mature miRNA primers and mRNA are described in Table I. They were all synthesized and purified by GenePharma Co.

Immunohistochemistry and in situ hybridization. Human NSCLC tissue specimens and nude mouse xenografts were fixed in formalin and embedded in paraffin for preparation of tissue sections for immunohistochemistry and in situ hybridization. Tissue sections 4-6- $\mu \mathrm{m}$ thick were dewaxed and re-hydrated. For immunohistochemistry, the sections were heated in a microwave in an antigen retrieval buffer $(0.01 \mathrm{M}$ citrate buffer, $\mathrm{pH}$ 6.0) for $5 \mathrm{~min}$, incubated in $3 \% \mathrm{H}_{2} \mathrm{O}_{2}$ solution in phosphate-buffered saline (PBS) at room temperature for 30 min to block potential endogenous peroxidase activity, and then incubated in $20 \%$ normal goat serum to block nonspecific binding of the secondary antibody. Then the tissue sections were incubated with a primary antibody, Smad3 at a dilution of 1:50; CD44 at a 1:50 dilution (both from Cell Signaling Technology, Danvers, MA, USA, or K-Ras from Millipore, Billerica, USA at a 1:50 dilution) at $4^{\circ} \mathrm{C}$ overnight in a humidified chamber. The next day, after washing with PBS three times, the sections were further incubated with a biotinylated goat anti-rabbit IgG antibody (UltraSensitive S-P kit, Maixin Biotechnology Co., Fuzhou, China).

For in situ hybridization, the rehydrated tissue sections were transferred into a $3 \% \mathrm{H}_{2} \mathrm{O}_{2}$ and protease buffer for inactivation of endogenous peroxidase. The sections were then treated with pepsin solution diluted in 3\% citric acid, and were hybridized overnight at $59^{\circ} \mathrm{C}$ with a $50 \mathrm{nM}$ DIG-labeled locked nucleic acid (LNA)-based probe specific for miR-143 or LNA-src-miR negative control probe (Exiqon, Vedbaek, Denmark). After rinsing in the washing buffer, the sections were blocked in blocking buffer. An antibody specific for DIG-AP Fab fragments antibody was applied to the sections.

For color reaction, both immunohistochemical and hybridized sections were then washed and incubated in 3'-diaminobenzidine hydrochloride (DAB) solution and then briefly counterstained with haematoxylin solution. The sections were then dehydrated and mounted for review and scoring under an Olympus microscope (Model BX-51, Tokyo, Japan). For negative and blank control of immunohistochemistry, goat serum and PBS were used to replace the primary antibody, respectively. A semi-quantitative scoring criterion was used for these sections, in which two pathologists independently in a blinded manner recorded staining intensity and percentage of positively stained tumor cells. For the staining intensity, we used 0 to represent no staining, 1 for weak staining, 2 for positive staining, and 3 for strongly positive staining. For percentage values, we scored the sections as 1 for $0-25 \%$ stained, 2 for $26-50 \%$ stained, 3 for $51-75 \%$ stained, and 4 for $76-100 \%$ stained tumor cells. The sum of both counts was used as the final score for each case. A total score $<8$ was considered a low level of expression, while a total score $\geq 8$ was considered high-level expression.

siRNA and transfection into NSCLC cells. To knock down Smad 3 expression in NSCLC cells, we utilized Smad3 siRNA; for a negative control, we used non-targeting scrambled siRNA (both from Qiagen). Smad3 siRNA and control siRNA $(40 \mathrm{nM})$ were then transfected into NSCLC cells using RNAi Max kit (Qiagen) according to the manufacturer's instructions. After $24 \mathrm{~h}$, the cells were used for phenotypic and gene expression experiments.

Cell viability MTT assay. Cells were seeded at a density of $5 \times 10^{3}$ cells/well in 96-well plates $24 \mathrm{~h}$ after siRNA transfec- 
Table I. Primer sequences.

\begin{tabular}{|c|c|}
\hline Primer & Primer sequences \\
\hline \multicolumn{2}{|l|}{ miRNA primers } \\
\hline $\operatorname{miR}-143$ & 5'-TGAGATGAAGCACTGTAGCTC-3' \\
\hline miR-145 & 5'-GTCCAGTTTTCCCAGGAATCCCT-3' \\
\hline miR-181a-2 & 5'-AACATTCAACGCTGTCGGTGAGT-3' \\
\hline $\operatorname{miR}-487 b$ & 5'-GTGGTTATCCCTGTCCTGTTCG-3' \\
\hline miR-1972 & 5'-TCAGGCCAGGCACAGTGGCTCA-3' \\
\hline $\operatorname{miR}-138$ & 5'-AGCTGGTGTTGTGAATCAGGCCG-3' \\
\hline $\operatorname{miR}-21$ & 5'-TAGCTTATCAGACTGATGTTGA-3' \\
\hline $\operatorname{miR}-1246$ & 5'-AATGGATTTTTGGAGCAGG-3' \\
\hline \multicolumn{2}{|l|}{ mRNA primers } \\
\hline \multirow[t]{2}{*}{ Smad3 } & F 5'-CCCCAGAGCAATATTCCAGA-3' \\
\hline & R 5'-GGCTCGCAGTAGGTAACTGG-3' \\
\hline \multirow[t]{2}{*}{ CD44 } & F 5'-AAGGTGGAGCAAACACAACC-3' \\
\hline & R 5'-AGCTTTTTCTTCTGCCCACA-3' \\
\hline \multirow[t]{2}{*}{ K-Ras } & F 5'-TGTGGTAGTTGGAGCTGGTG-3' \\
\hline & R 5'-TGACCTGCTGTGTCGAGAAT-3' \\
\hline Pri-miR-143/ & F 5'-AACTCCAGCTGGTCCTTAG-3' \\
\hline 145 & R 5'-TCTTGAACCCTCATCCTGT-3' \\
\hline \multirow[t]{2}{*}{ GAPDH } & F 5'-AAGGTGAAGGTCGGAGTC-3' \\
\hline & R 5'-GATTTTGGAGGGATCTCG-3' \\
\hline
\end{tabular}

tion and incubated for $24 \mathrm{~h}$. After that, $20 \mu \mathrm{l}$ of MTT solution $(5 \mathrm{mg} / \mathrm{ml})$ was added to each well, and the cell culture plates were further incubated for additional $4 \mathrm{~h}$ at $37^{\circ} \mathrm{C}$. The growth medium was removed and replaced with $150 \mu \mathrm{l}$ of dimethyl sulfoxide (DMSO) in each well to dissolve MTT formaz crystals for $10 \mathrm{~min}$; optical density (OD) was measured using a scanning multi-well spectrophotometer at a wavelength of $490 \mathrm{~nm}$. Six parallel wells were measured each time, and the experiment was repeated three times.

Wound healing assay. Cells were transfected with miR-143 mimics and grown to $90 \%$ confluency in a 6-well dish. A wound was created using a sterile $10-\mu 1$ pipette tip, followed by a wash with $1 \mathrm{X}$ PBS to remove detached cells. The cells were then further cultured in the growth medium containing $5 \%$ FCS for up to $48 \mathrm{~h}$, during which cell migration at the corresponding wound site was documented using a Nikon microscope (Nikon) at 0, 24 and $48 \mathrm{~h}$. The wound distance was then measured, and the mean and standard deviation of each treatment were determined.

Tumor cell Transwell invasion assay. Corning Costar Transwell 24-well plate inserts (8- $\mu$ m pores; Corning) were coated with $20 \mu \mathrm{l}$ of Matrigel (BD, New York, USA) and placed in the cell culture hood for $1 \mathrm{~h}$ at $37^{\circ} \mathrm{C}$. Cells $\left(2 \times 10^{4}\right)$ were then seeded into the upper chambers of the inserts after transfections, while normal growth medium was placed in the bottom chambers. Cells were then allowed to grow for 24 or $48 \mathrm{~h}$. The invaded cells were fixed in $100 \%$ methanol for $1 \mathrm{~min}$ and allowed to air dry. Invasive cells on the lower surface of the membrane were stained by dipping inserts in $1 \%$ crystal violet staining solution for 2 min and were counted.
Specifically, five randomly selected 20x microscopic fields of cells were counted per insert.

Nude mouse xenograft assay. Nude mice were obtained from Slaccas Co. (Shanghai, China), and the A549 cells overexpressing LAN-miR-143 were injected subcutaneously $\left(1 \times 10^{6}\right.$ cells per mouse with five mice per group). After that, the mice were monitored for xenograft formation and growth for 21 days. At the end of experiments, the mice were sacrificed and xenografts were removed and weighed.

Luciferase report assay. We first performed bioinformatical analysis of miR-143-targeted genes using web tools (such as TargetScan and pictar) and found Smad3, CD44, and K-Ras as the putative miR-143-targeted genes. We then constructed a PMIR vector carrying Smad3, CD44, K-Ras-binding site sequences or their deletion mutation sequences. Binding of miR-143 to these gene sequences was assessed using a Luciferase reporter system from Sigma Chemical Co. (St. Louis, MO, USA) according to the kit instructions.

Protein extraction and western blotting. Protein extraction and western blotting were performed as described previously (11). Protein samples (50 $\mu \mathrm{g}$ each) were resolved on $10 \%$ SDS-polyacrylamide gels. The proteins were then transferred onto PVDF membranes, incubated with 5\% skim milk at room temperature in TBS-T (20 mM Tris- $\mathrm{HCl}, \mathrm{pH} 7.5$, $500 \mathrm{mM} \mathrm{NaCl}(13,14)$, and $0.1 \%$ Tween-20), and then further incubated at $4^{\circ} \mathrm{C}$ overnight with a primary mouse monoclonal antibody against Smad3, CD44 or K-Ras (Cell Signaling Technologies, Cambridge, UK) at a dilution of 1:1,000, or a rabbit polyclonal anti- $\beta$-actin antibody from Boshide (Wuhan, China). After washing three times with TBS-T, the membranes were incubated with a secondary antibody for $1 \mathrm{~h}$ at room temperature. Finally, peroxide and luminol solutions of 40:1 were added to cover the whole membrane surface for $5 \mathrm{~min}$ at room temperature, and positive protein bands were visualized by placing the membrane in a developing cassette against X-ray film.

Statistical analysis. All experimental data were summarized as mean \pm standard deviation, if possible, and statistically analyzed using SPSS 17.0. (SPSS, Chicago, IL, USA). The Student's t-test was used to compare between two groups. Two-way ANOVA was used to compare differences among three or more experimental groups. All p-values were two-sided and values $<0.05$ were considered statistically significant.

\section{Results}

TGF- $\beta$ induces miR-143 expression in NSCLC cells. To explore the molecular mechanisms by which TGF- $\beta$ induces cell contractile phenotype in NSCLC cells, we first grew and treated A549 cells with either 400-pM TGF- $\beta$ or PBS (as a control) for $48 \mathrm{~h}$, and then performed a miRNA chip array analysis. We found 16 upregulated and 42 downregulated miRNAs in NSCLC cells after TGF- $\beta$ treatment. A heat map diagram analysis showed that the maximally upregulated miRNA was in the miR-143/145 cluster, and the maximally downregulated miRNA was miR-1972 (Fig. 1A). We then verified expression 

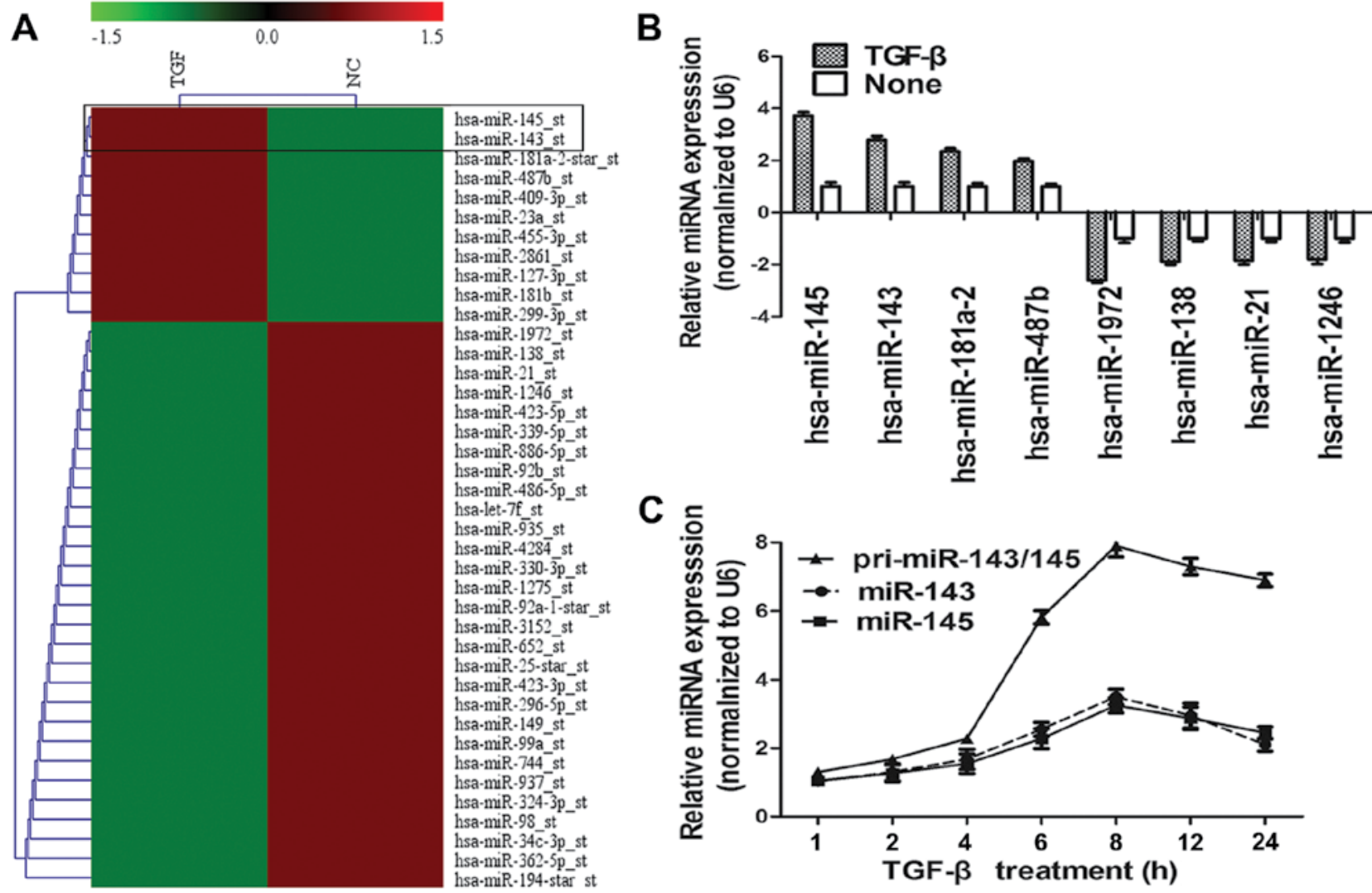

Figure 1. TGF- $\beta$ induction of miR-143/145 expression in NSCLC cells. (A) A heat map was generated after miRNA chip array analysis of NSCLC-treated with TGF- $\beta$ vs. PBS controls. Upregulated miRNAs (red) and downregulated miRNAs (green) changed by $\geq 1.5$ - and $\leq 0.75$-fold, respectively (p $\leq 0.05$ ). The black box indicates expression of miR-143 and miR-145. (B) NSCLC A549 cells were grown and treated with TGF- $\beta$ and subjected to qRT-PCR analysis of miRNA expression. (C) NSCLC A549 cells were grown and treated with TGF- $\beta$ for different periods of time, and then subjected to qRT-PCR analysis of miRNA expression.

A

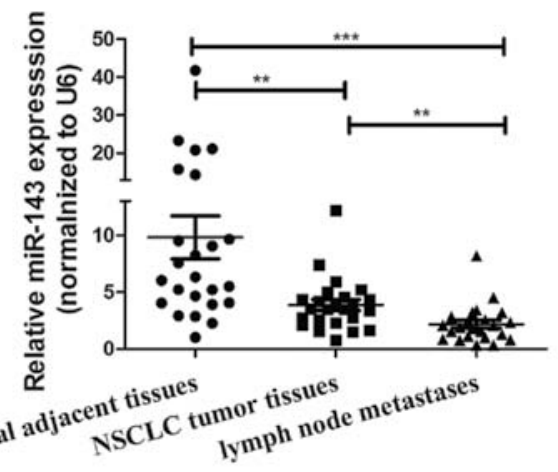

$\mathrm{C}$

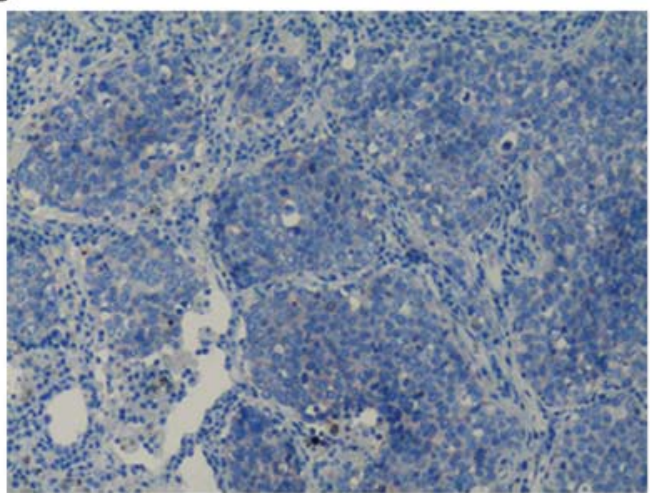

NSCLC tumor tissues

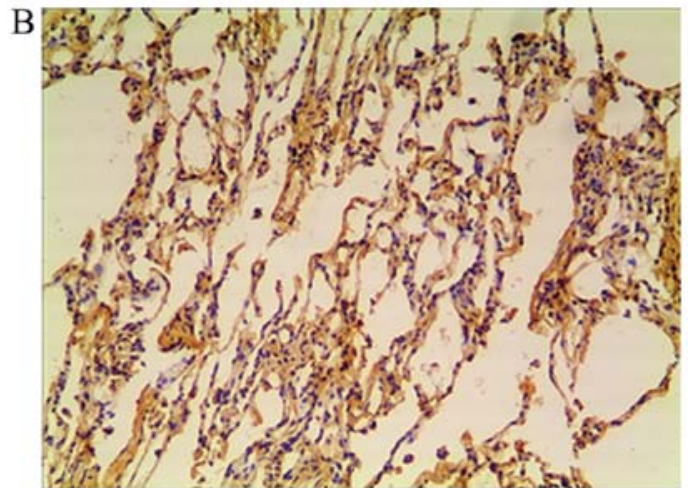

Normal adjacent tissues

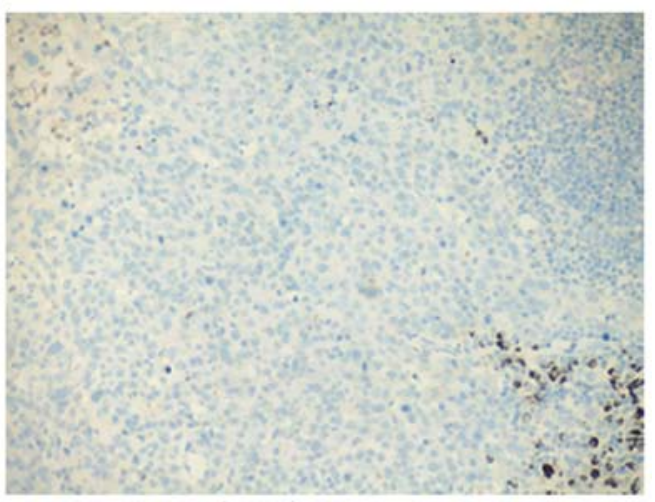

Lymph node metastases

Figure 2. Reduced miR-143 expression in NSCLC tissues. (A) qRT-PCR. (B-D) In situ hybridization. 
A

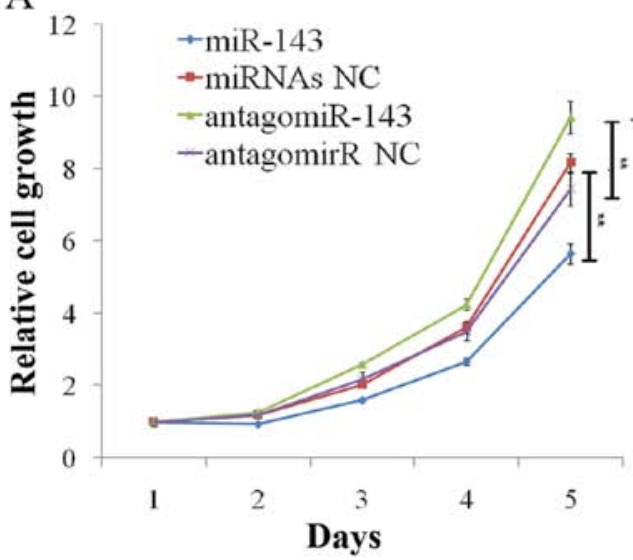

B
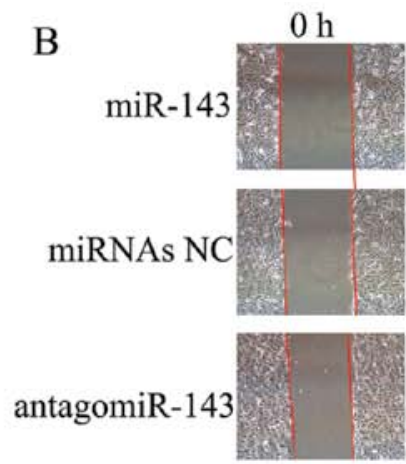

antagomirR NC
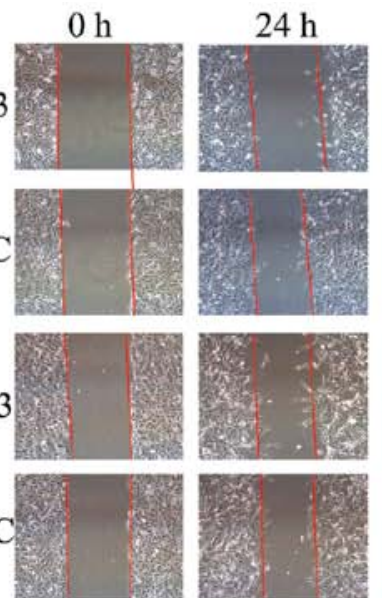

$48 \mathrm{~h}$
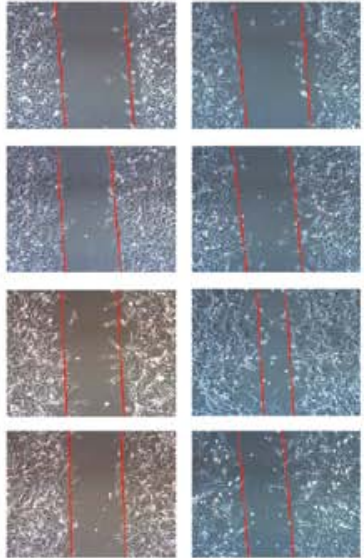

C

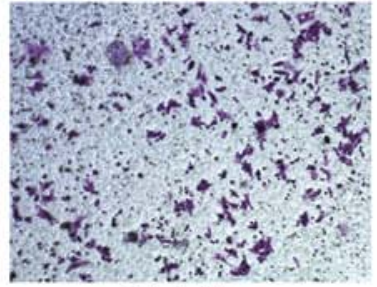

miR-143

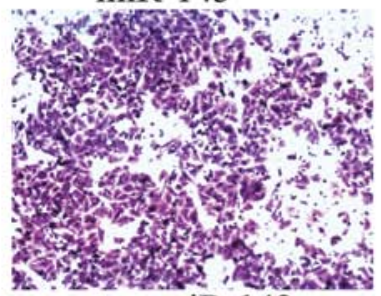

antagomiR-143

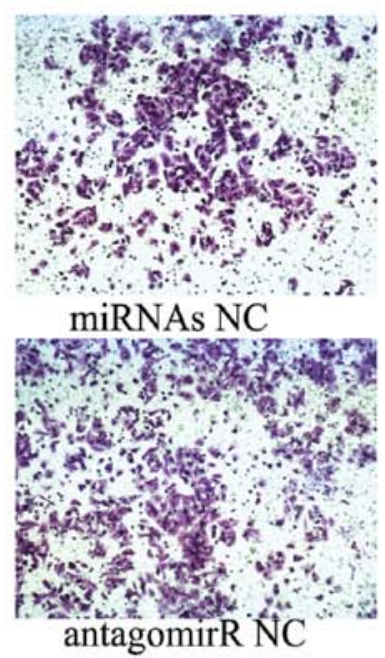

D

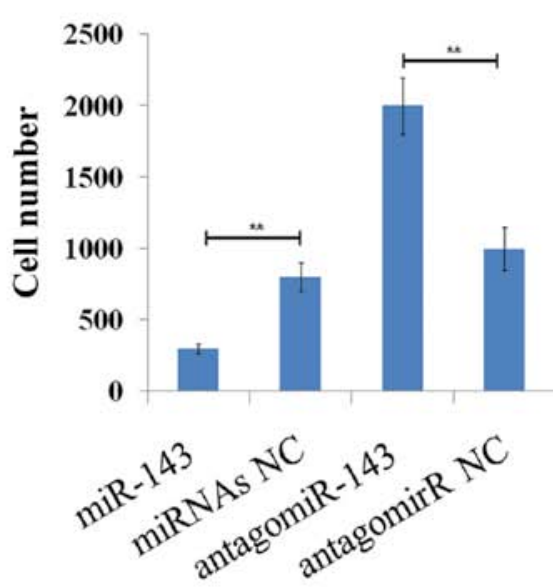

E

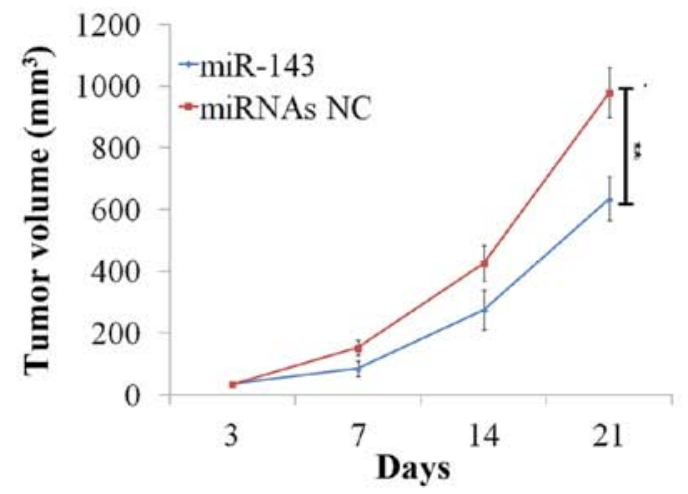

F

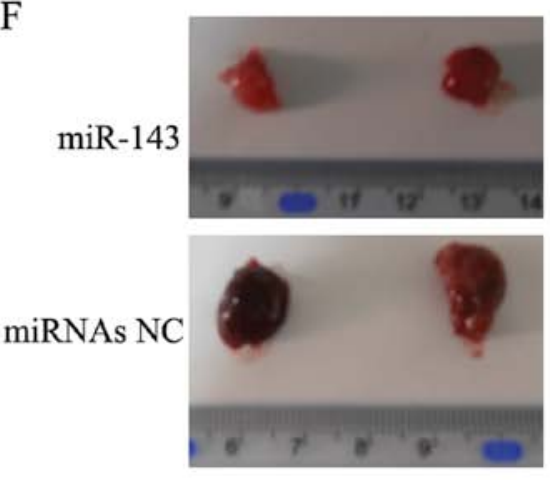

Figure 3. Effects of miR-143 expression on regulation of NSCLC growth in vitro and in nude mouse xenografts. (A) Cell viability assay. Overexpression of miR-143 resulted in reduction of A549 cell viability, whereas knockdown of miR-143 expression using antagomiR significantly increased A549 cell viability. (B) Wound healing assay. Overexpression of miR-143 delayed closure of the wound gap in a time-dependent manner, whereas miR-143 inhibitor promoted wound healing. (C and D) Tumor cell invasion assay. Overexpression of miR-143 significantly reduced tumor cell invasion capacity compared to the controls. (E and F) Tumor cell xenograft assay. Overexpression of miR-143 significantly reduced the size of tumor cell xenografts (E) or tumor volumes (F) compared to those of the control mice.

of four upregulated and four downregulated miRNAs using qPCR (Fig. 1B). We then assessed expression of the miR-143 cluster and pri-miR-143/145 in NSCLC cells after treatment with TGF- $\beta$ for different periods of time. Pri-miR-143/145 expression was dramatically upregulated after $4 \mathrm{~h}$ after TGF- $\beta$ treatment and reached a maximum at $8 \mathrm{~h}$ after treatment (a 7.9-fold increase, Fig. 1C).
Downregulation of miR-143 expression in NSCLC tissue specimens. To confirm the altered miR-143 expression ex vivo, we performed qRT-PCR analysis of miR-143 in 24 cases of matched NSCLC and the corresponding distant normal tissue specimens and in lymph node metastasized NSCLCs. As shown in Fig. 2A, levels of miR-143 expression were significantly reduced by $1.2-9.8$-fold in $87.5 \%$ (21 of 24) of NSCLC 
A

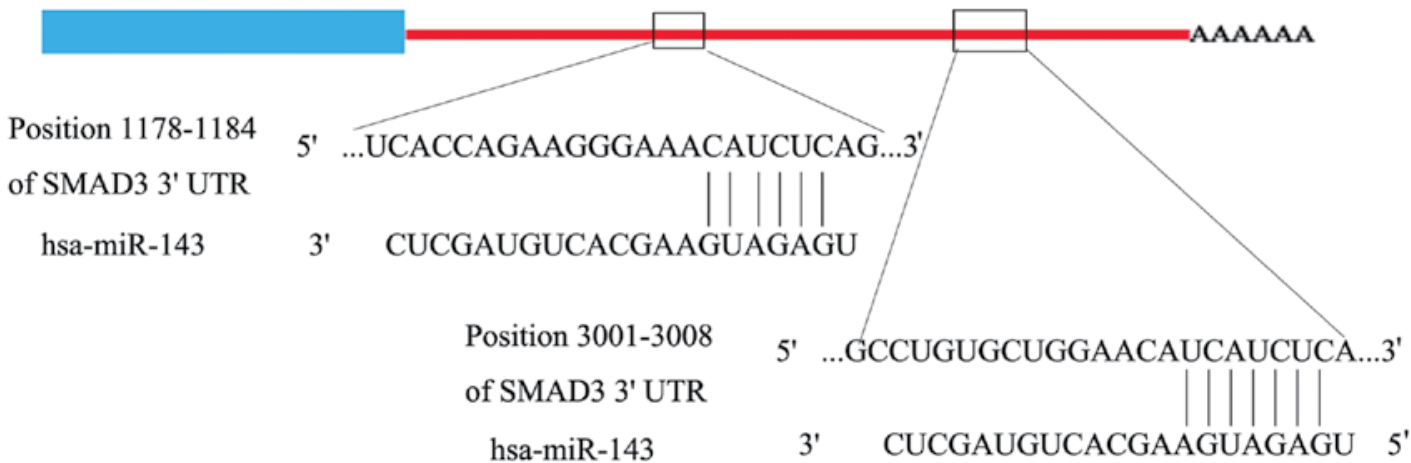

B

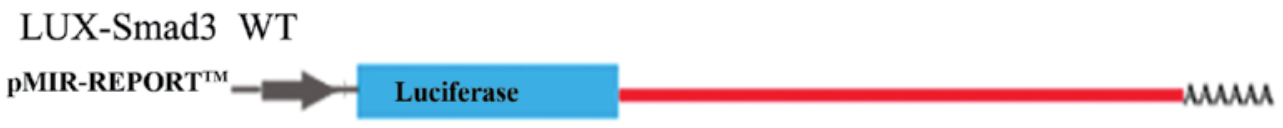

LUX-Smad3 MUT
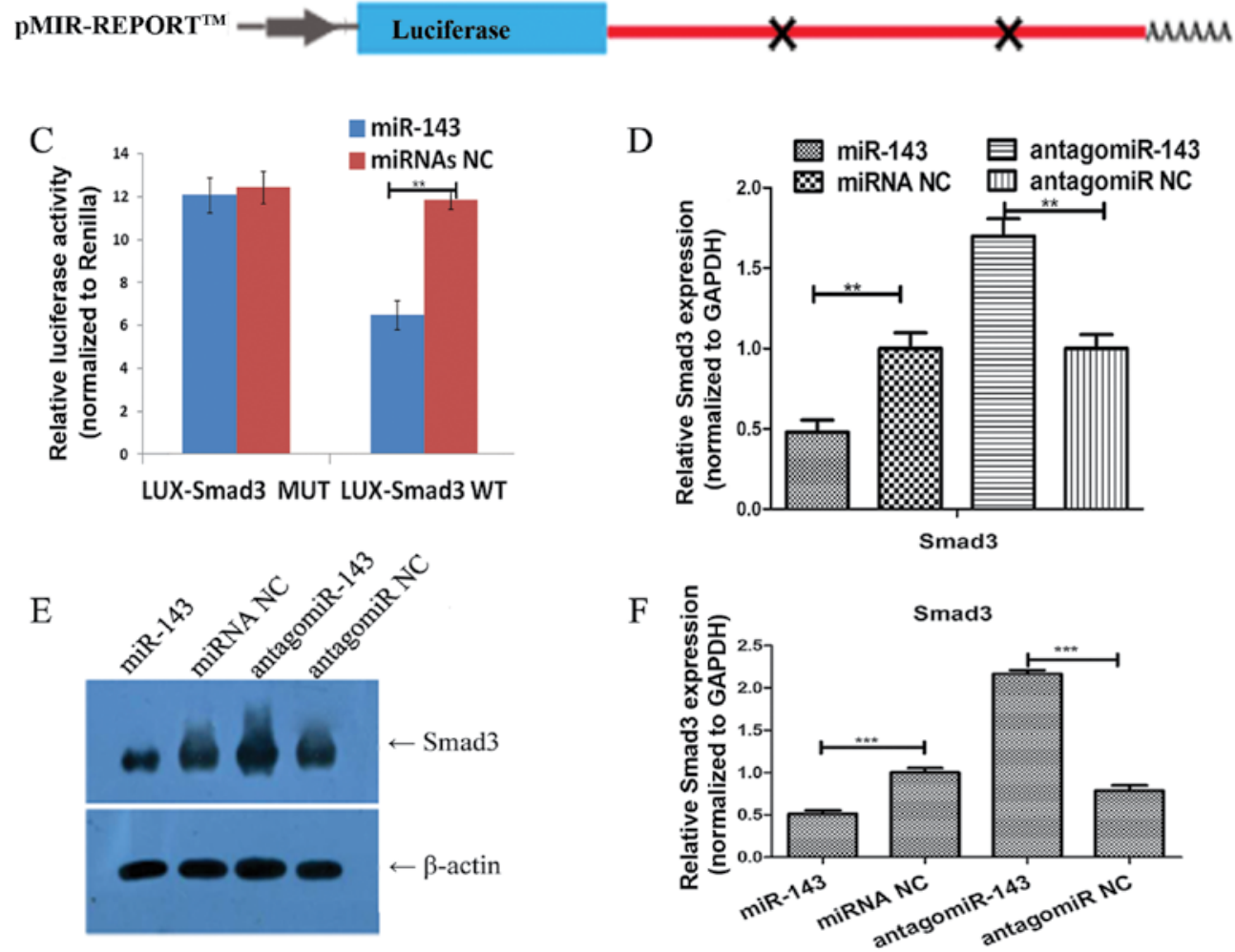

Figure 4. miR-143 downregulates Smad3 expression in NSCLC cells. (A) Bioinformatical analysis. Potential miR-143 binding sites at 3'-UTR of Smad3 (red), and the alignment of mature miR-143 sequences to the target sites 3'-UTR of Smad3. (B) Luciferase reporter constructs. The wild-type or mutant 3'-UTR of Smad3 was constructed according to miR-143 binding sites and cloned to the downstream of the luciferase open reading frame. (C) Luciferase activity assay. The data showed a significant decrease in luciferase activity in cells overexpressing miR-143, whereas the luciferase activity of the mutant Smad3 3'-UTR remained unchanged in cells. (D-F) qRT-PCR and western blot assays. The data showed that expression of miR-143 downregulated Smad3 expression in A549 cells, whereas antagomiR-143 treatment resulted in upregulated Smad3 expression.

tumor tissues compared to the corresponding distant normal lung tissues; miR-143 expression was further reduced by 1.5-65.7-fold in $91.7 \%$ (22 in 24) of lymph node metastasized NSCLCs (Fig. 2A). Next, we assessed expression of miR-143 in a panel of NSCLC tissue specimens using in situ hybridization with similar findings (Fig. 2B).

Effects of miR-143 on regulation of A549 cell viability and invasion capacity. To explore the role of miR-143 in NSCLC cells, we transfected miR-143 mimics (miR-143) and negative controls (miR-NC), or miR-143 inhibitors (antagomiR-143) and inhibitor controls (antagomiR NC) into A549 cells. Expression of miR-143 inhibited A549 cell viability, whereas miR-143 inhibitors increased A549 cell viability (Fig. 3A). Moreover, during tumor cell wound healing assays, overexpression of miR-143 significantly delayed closure of the wound in a time-dependent manner, whereas miR-143 inhibitor promoted the wound healing (Fig. 3B). During a 
A

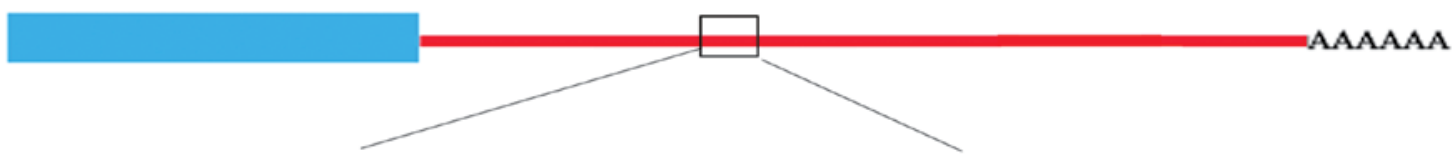

Position 795-802 5' ...GACUCUUCUAAGUCUUCAUCUCA... 3'

of CD44 3' UTR

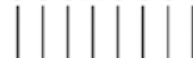

hsa-miR-143

3' CUCGAUGUCACGAAGUAGAGU ...5'

B

LUX- CD44 WT

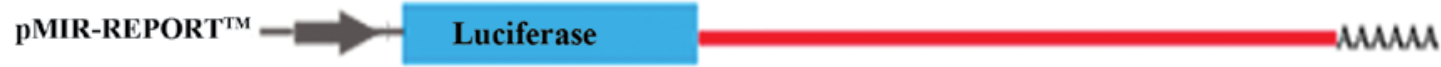

LUX- CD44 MUT

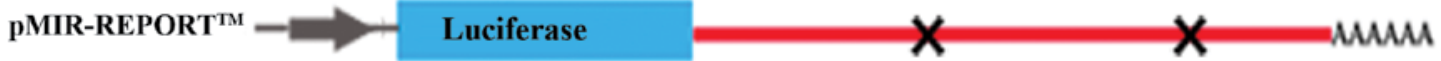

$\mathrm{C}$

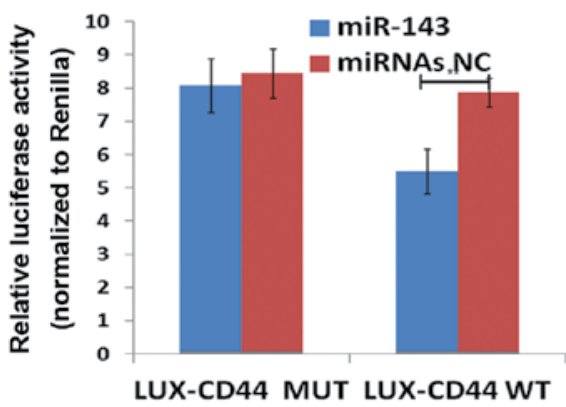

E

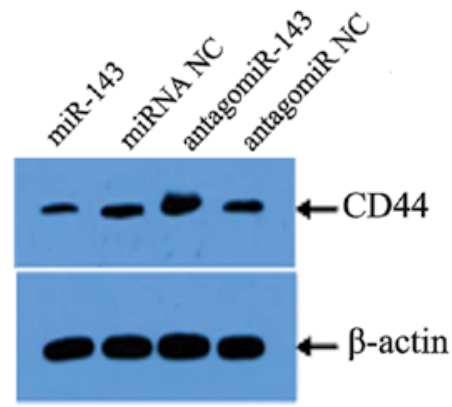

D

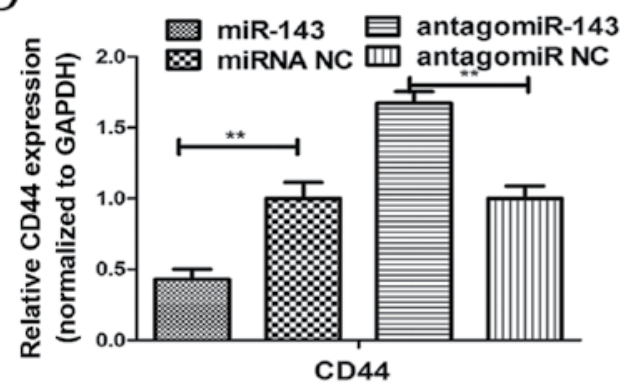

F

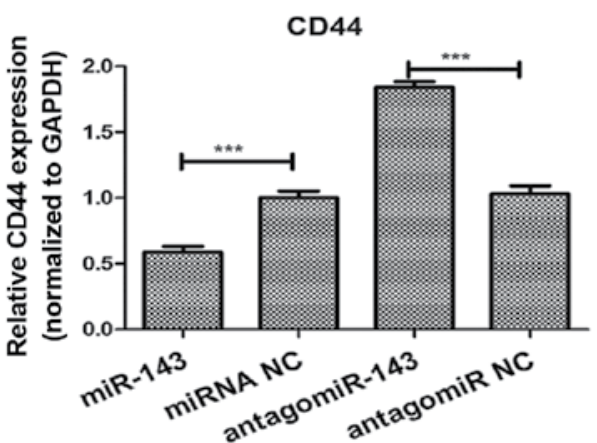

Figure 5. miR-143 downregulation of CD44 expression in NSCLC cells. (A) Schematic representation of CD44 3'-UTR. The red bars show the predicted miR-143 binding sites of CD44 3'-UTR and alignment of the mature miR-143 sequence to the target sites of CD44 3'-UTR. (B) Luciferase reporter constructs. Both wild-type and mutant CD44 3'-UTR were cloned downstream of the luciferase open reading frame. (C) Luciferase assay. There was a significant decrease in luciferase activity in cells overexpressing miR-143, whereas the luciferase activity in the mutant CD44 3'-UTR remained unchanged in cells. (D) qRT-PCR. miR-143 downregulated expression of CD44 in A549 cells, whereas antagomiR-143 treatment resulted in upregulation of CD44 expression. (E and F) Western blotting. miR-143 downregulated the expression of CD44 in A549 cells, whereas antagomiR-143 treatment upregulated CD44 expression.

Transwell tumor cell invasion assay, the number of cells transfected with miR-143 mimics that passed through the $8-\mu \mathrm{m}$ pore insert underneath the well was significantly less than the number of cells transfected with negative control. The miR-143 inhibitor obviously promoted the invasion capacity of A549 cells (Fig. 3C and D).

The in vivo role of miR-143 in tumor cell growth was also assessed using a nude mouse xenograft assay. Following subcutaneous injection of LAN-miR-143-overexpressed A549 cells into nude mice, xenografts from miR-143-overexpressedA549 cells were much smaller than those from control mice $(n=4-5 /$ group, $p<0.05$; Fig. $3 E$ ). The tumor volume of xeno- grafts from miR-143-overexpressed A549 cells was also smaller than from control cells (Fig. 3F).

miR-143 downregulation of Smad3, CD44, and K-Ras expression in NSCLC cells. To elucidate the underlying molecular events of miR-143 expression in NSCLC cells, putative target genes of miR-143 were searched using online algorithms for miRNA target prediction (i.e., Pictar, RNAhybrid, and TargetScan). We found that Smad3, CD44, or K-Ras could be the target gene. The schematic diagram of miR-143 binding sites in Smad3 3'-UTR is shown in Fig. 4A. To verify the diagram, we constructed a luciferase reporter vector using 
A

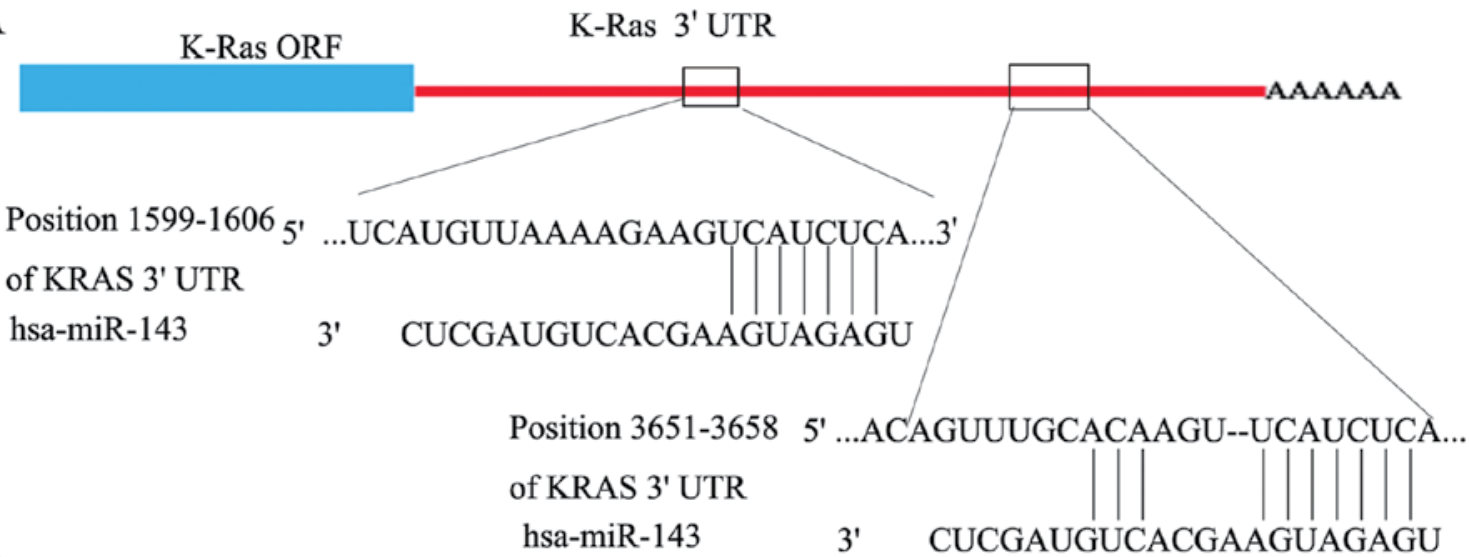

B

LUX- K-Ras WT
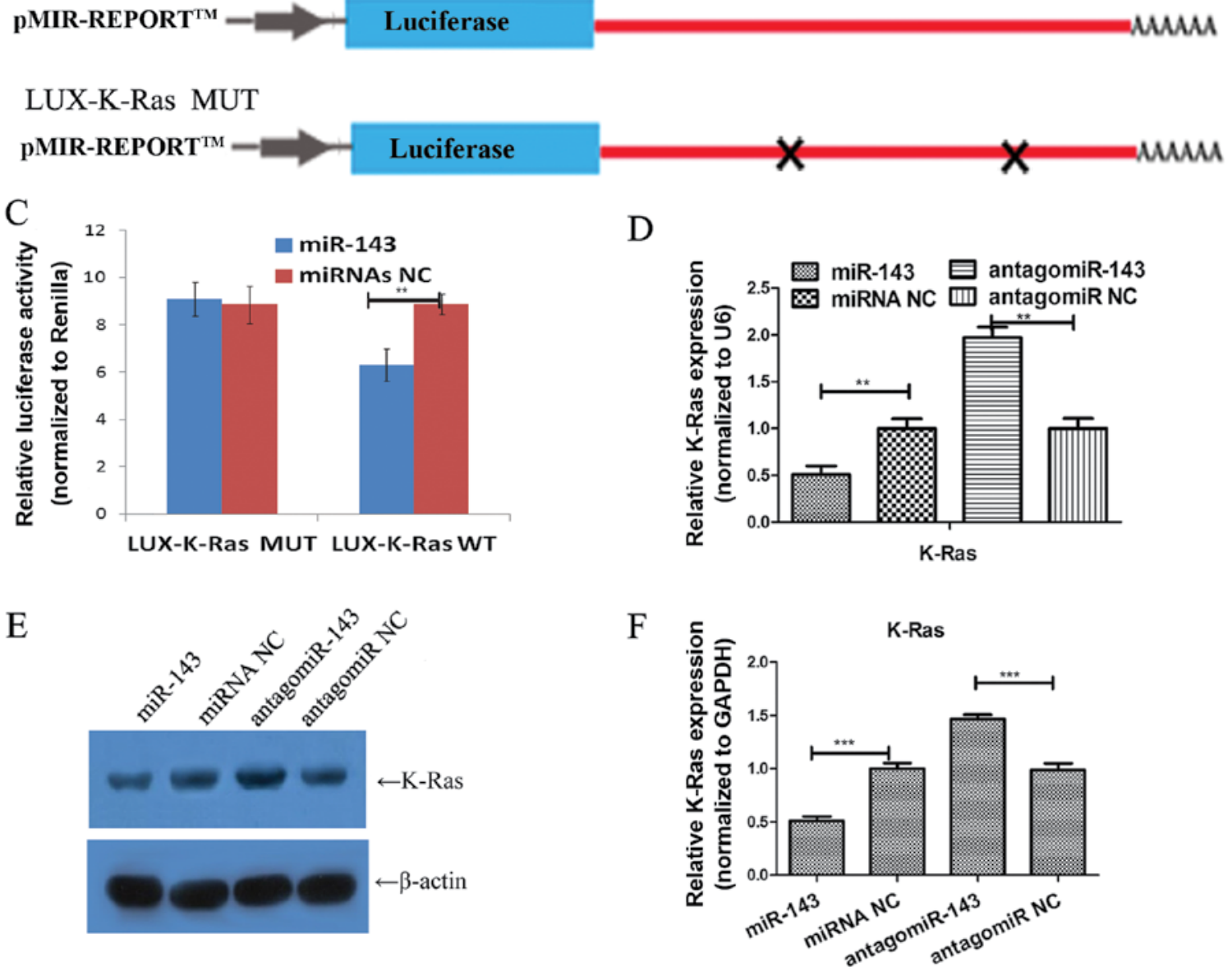

Figure 6. miR-143 downregulation of K-ras expression in NSCLC cells. (A) Schematic representation of K-ras 3'-UTR. The red bars show the predicted miR-143 binding sites of K-ras 3'-UTR and alignment of the mature miR-143 sequence to the target sites of K-ras 3'-UTR. (B) Luciferase reporter constructs. Both wild-type and mutant K-ras 3'-UTR were cloned into the downstream of the luciferase open reading frame. (C) Luciferase assay. The data showed a significant decrease in luciferase activity in cells overexpressing miR-143, whereas the luciferase activity in the mutant K-ras 3'-UTR remained unchanged in cells. (D) qRT-PCR. miR-143 downregulated expression of K-ras in A549 cells, whereas antagomiR-143 treatment resulted in upregulation of K-ras expression. (E and F) Western blotting. miR-143 downregulated the expression of K-ras in A549 cells, whereas antagomiR-143 treatment upregulated K-ras expression.

cloned Smad3 3'-UTR, both wild-type and mutant sequences (Fig. 4B), and performed gene transfection and a luciferase assay. We observed a significant decrease in luciferase activity in cells overexpressing miR-143. In contrast, luciferase activity of mutant 3'-UTR remained unchanged in cells overexpressing miR-143 (Fig. 4C), indicating that miR-143 did bind to Smad3 3'-UTR. After that, we performed qRT-PCR and western blot analyses to confirm that miR-143 overexpression inhibited expression of endogenous Smad3 mRNA and protein, in NSCLC A549 cell lines. The knockdown of miR-143 expression resulted in upregulation of endogenous Smad3 expression (Fig. 4D-F).

Furthermore, miR-143 binding sites in CD44 and K-Ras 3'-UTR were also analyzed (Figs. 5 and 6). The luciferase 


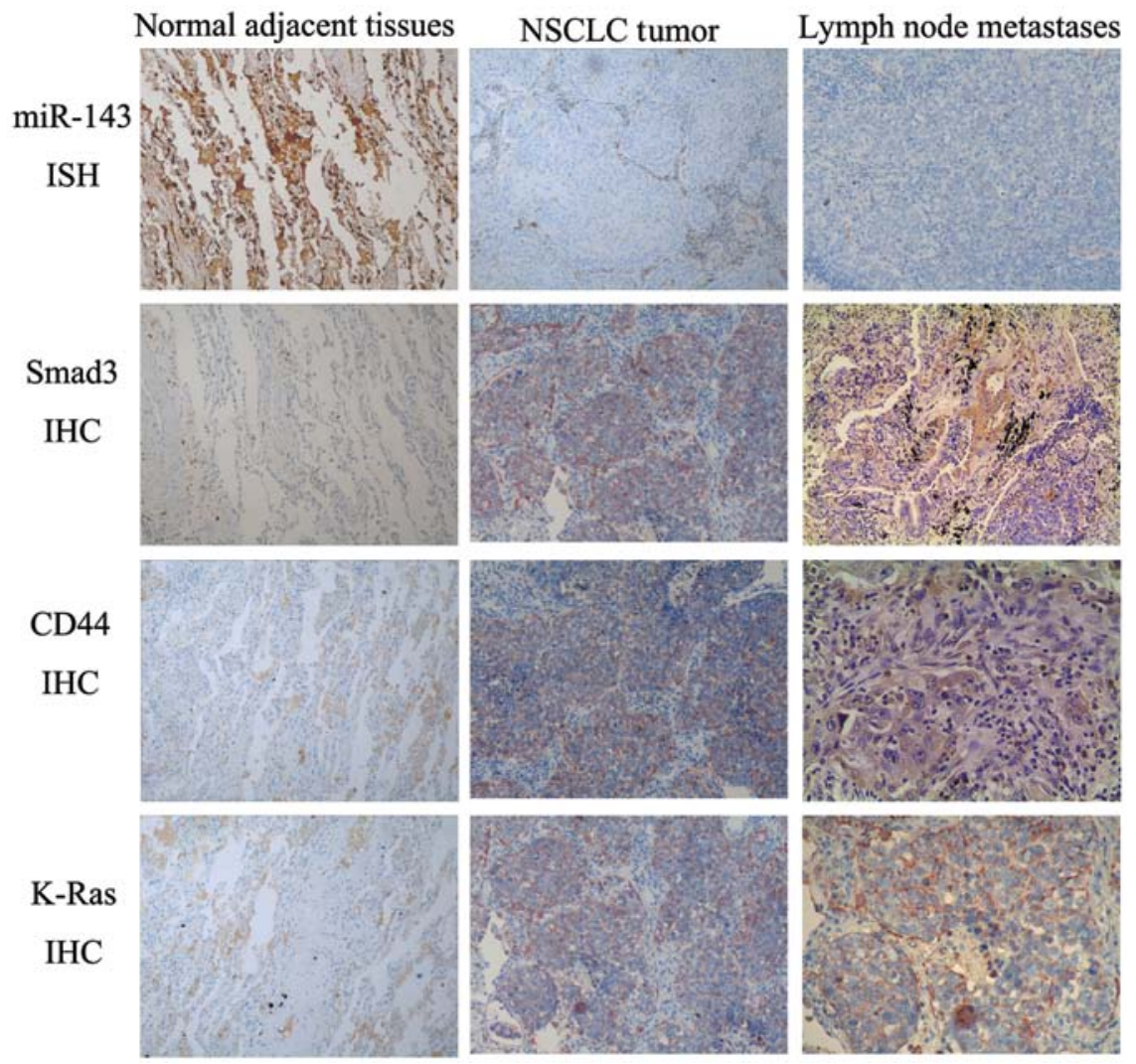

Figure 7. Expression of miR-143 and the target genes (e.g., Smad3, CD44 and K-Ras) in NSCLC tissues and cells. TGF- $\beta$ induced miR-143 but inhibited Smad3, CD44, and K-Ras expression in NSCLC cells (ISH, in situ hybridization; IHC, immunohistochemistry).

assay also verified miR-143 binding to CD44 and K-Ras 3'-UTR. qRT-PCR and western blotting confirmed that these two molecules were also regulated by miR-143.

We also verified the regulation of Smad3, CD44 and K-Ras in ex vivo tissue specimens and A549 cell xenografts using in situ hybridization and immunohistochemistry. There was an association between miR-143 expression and the target genes (Smad3, CD44 and K-Ras) in the NSCLC and normal lung tissues and lymph node metastatic tissues as well (Fig. 7). Subcutaneous A549 xenografts displayed similar results (Fig. 8).

To assess the coordinated effects of TGF- $\beta$ on regulation of miR-143 and Smad3 expression, we first analyzed expression of miR-143 and Smad3 in A549 cells after varying periods of TGF- $\beta$ treatment. Expression of miR-143 was slowly upregulated by TGF- $\beta$ from 1 to $8 \mathrm{~h}$ and reached a maximum after $8 \mathrm{~h}$ of treatment. The opposite trend was observed for expression of CD44 and K-Ras expression, which were downregulated at each time point from $1 \mathrm{~h}$ to $24 \mathrm{~h}$ (Fig. 9A). Smad3 expression, however, was upregulated during the first $4 \mathrm{~h}$, and then downregulated from 6 to $24 \mathrm{~h}$. Smad3, as a signal transducer that is critical for transcriptional regulation by TGF- $\beta$, was first stimulated by TGF- $\beta$, but later was downregulated by expression of miR-143 that had been induced by TGF- $\beta$.

Furthermore, we knocked down Smad3 expression in A549 cells using Smad3 siRNA (si-Smad3) followed by TGF- $\beta$ treatment which resulted in $85 \%$ suppression of Smad3 expression (Fig. 9A), induction of miR-143 expression by TGF- $\beta$ was not different than in TGF-treated cells; the TGF- $\beta$ treatment

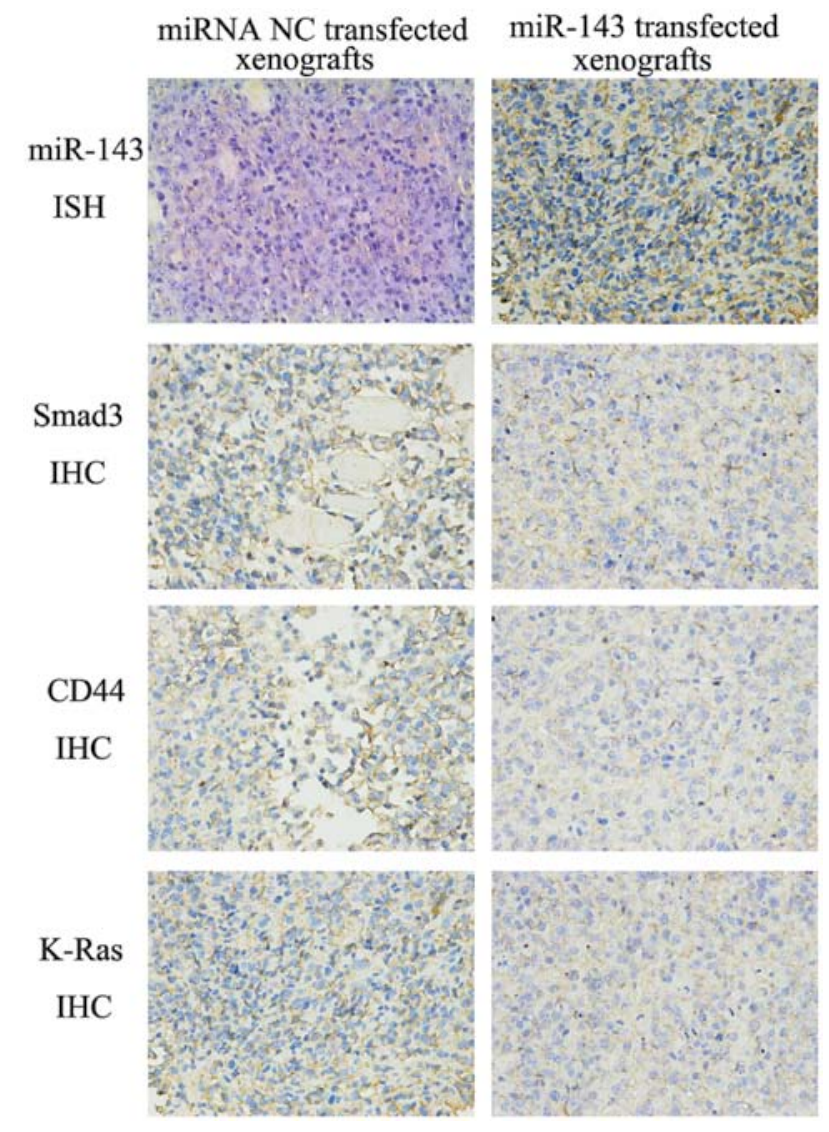

Figure 8. Expression of miR-143 and its target genes (i.e., Smad3, CD44 and K-Ras) in the xenografts. ISH, in situ hybridization; ICH, immunohistochemistry. 

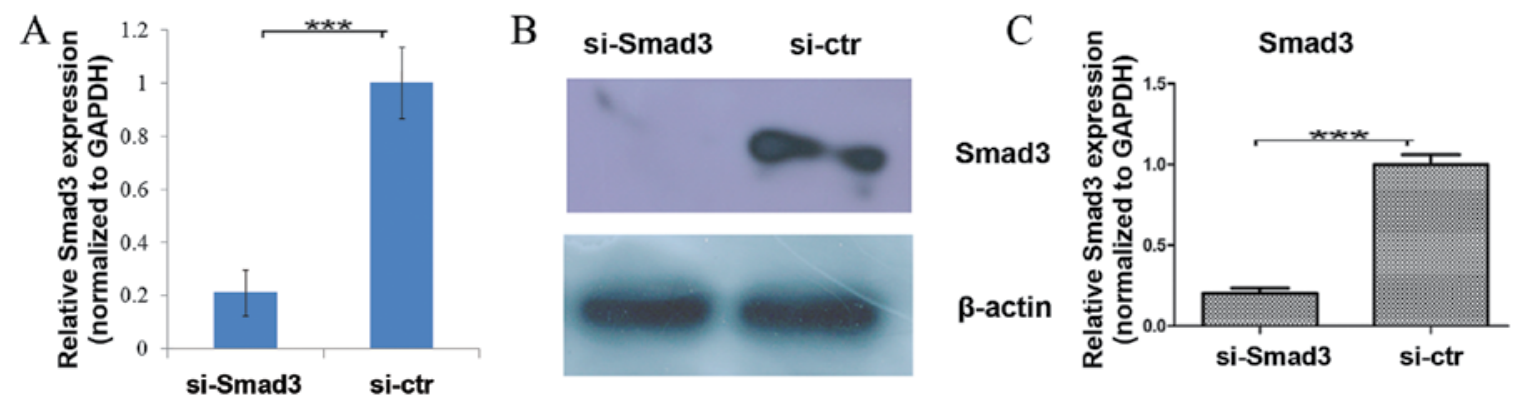

$\mathrm{D}$
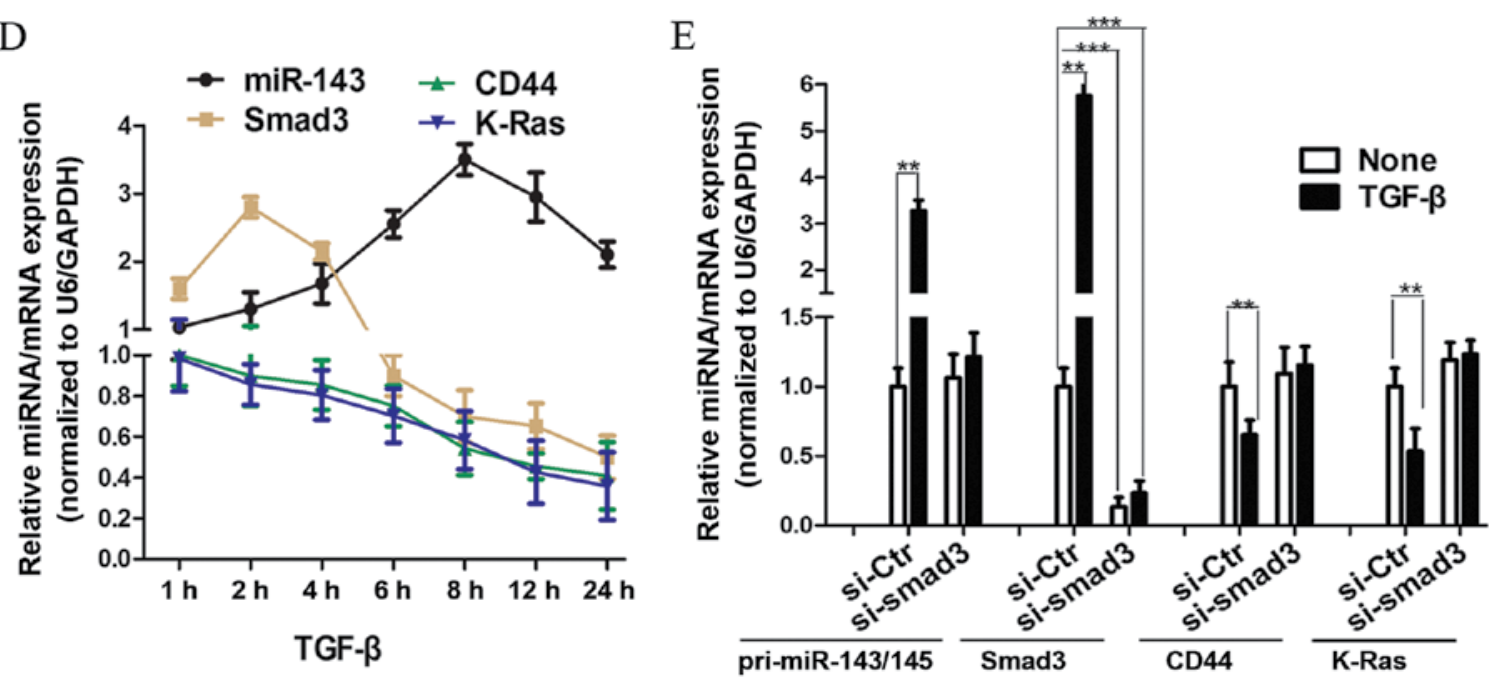

Figure 9. TGF- $\beta$ regulated miR-143, Smad3, CD44, and K-Ras expression in NSCLC cells. (A) qRT-PCR. The effect of Si-Smad3 on A549 cells was verified by qRT-PCR. (B and C) Western blotting. The effect of Si-Smad3 on A549 cells was verified by western blotting. (D) qRT-PCR. A549 cells were grown and treated with TGF- $\beta$ for different periods of time and then subjected to qRT-PCR analysis of miR-143, Smad3, CD44, and K-Ras expression. (E) The expression of pri-miR-143/145 and other molecules was induced by TGF- $\beta$ in the A549 cells after Smad3 knockdown.

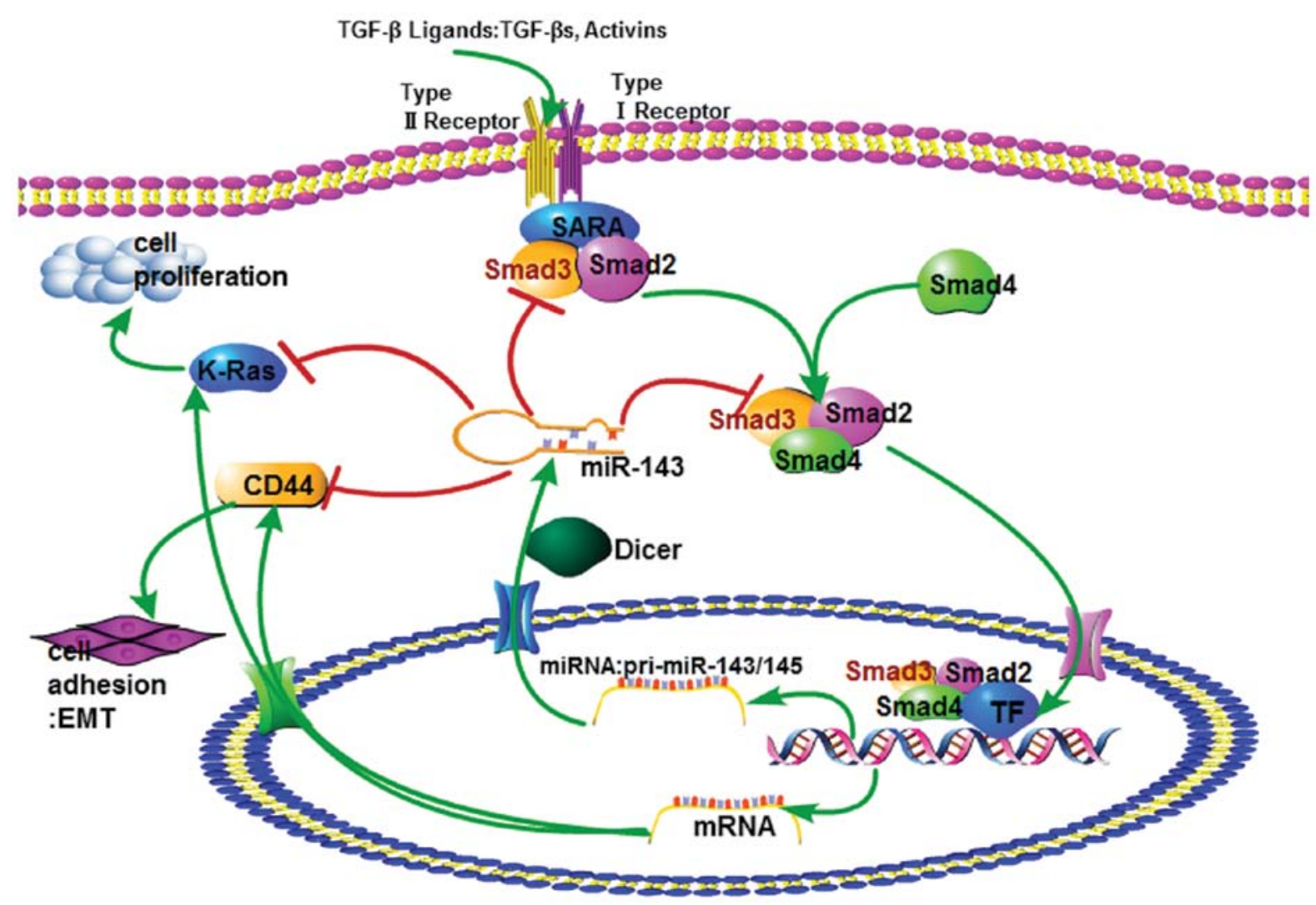

Figure 10. Schematic depiction of the TGF- $\beta / \mathrm{miR}-143 / \mathrm{Smad} 3$ circle loop. 
induced the pri-miR-143/145 expression without si-Smad3 in A549 cells. This would suggest that Smad3 plays a critical role in transcriptional activation of miR-143 expression (Fig. 6D). TGF- $\beta$-induction of CD44 and K-Ras mRNAs was abolished in si-Smad4-transfected cells (Fig. 9E).

\section{Discussion}

TGF- $\beta$ is secreted by many types of normal cells, and the TGF- $\beta$ signaling pathway can inhibit cell cycle progression at the G1 phase and therefore, suppress cell proliferation, but induce cell differentiation, and promote apoptosis $(13,14)$. However, after transformation into cancer cells, the cells will alter expression of TGF- $\beta$ and its signaling pathway. Moreover, TGF- $\beta$ secretion is also induced in tumor-surrounding stoma cells and TGF- $\beta$ acts on tumor stoma cells, such as fibroblasts, immune cells, endothelial and smooth-muscle cells causing tumor cell EMT, immune suppression and angiogenesis for cancer progression $(25,26)$. In addition, previous studies showed that miR-143 expression is downregulated in various cancers, including lung cancer. For example, Yanaihara et al reported that miR-143 expression was significantly decreased in 104 pairs of lung cancer tissues (27). Gao et al detected low expression of miR-143 in lung cancer tissues using qRT-PCR (28). Ma et al also found reduced levels of miR-143 expression NSCLC tissues and cells (29). Thus, in this study, we investigated the role of these molecules in NSCLC progression. We first treated NSCLC A549 cells with TGF- $\beta$; miRNA array analysis showed upregulation of miR-143, but our ex vivo data showed and confirmed downregulation of miR-143 in NSCLC tissues and lymph node-metastatic tissues. These data support antitumor effects of TGF- $\beta$-induced miR-143 in NSCLC cells.

In order to verify antitumor effects of miR-143 in NSCLC cells, we over-expressed miR-143 in A549 cells and observed significantly reduced NSCLC cell viability and invasion. Wound healing capacity in vitro and xenograft formation and growth in nude mice further supported the notion of miR-143 as a tumor suppressor gene in NSCLC. We then searched for the target gene of miR-143 using Pictar, RNAhybrid, and TargetScan and identified CD44, K-Ras and Smad3 as potential target genes. CD44 and K-Ras were confirmed as the target genes of miR-143 by previous studies $(11,29-31)$. CD44 is a cell-surface glycoprotein involved in cell-cell interactions, adhesion, and migration $(32,33)$. It is a receptor for hyaluronic acid (HA) and can also interact with other ligands, such as osteopontin, collagens, and matrix metal lipoproteinases (MMPs). CD44 has a wide variety of cellular functions, including lymphocyte activation, recirculation and homing, hematopoiesis, and tumor metastasis (32-34). $\mathrm{K}$-Ras is a member of the small GTPase super family. The RAS (rat sarcoma)/MAPK (mitogen-activated protein kinase) pathway plays a key role in regulation of various physiological cellular processes, including proliferation, differentiation, and cell death. Aberrant mutational activation of K-Ras/MAPK signaling is closely linked to cancer development in many organs in humans and laboratory animals $(23,35)$. We confirmed that expression of miR-143-inhibited expression of CD44 and K-Ras in NSCLC cells. Thus, NSCLC cell viability might be due to downregulation of K-Ras, while
miR-143-inhibited NSCLC cell invasion capacity might be due to downregulation of CD44. In addition, one important element of the TGF- $\beta$ pathway, Smad3, is also a target gene of miR-143 that has not been reported to date. In the present study, we verified that miR-143 bound to Smad3 3'UTR, and expression of miR-143 reduced Smad3 expression in NSCLC cells. There was an inverse association between miR-143 and Smad3, CD44, and K-Ras in NSCLC tissue specimens and A549 xenografts.

TGF- $\beta$ plays different roles in normal cells vs. tumors. For example, TGF- $\beta$ acts as a tumor suppressor in normal tissues or in early carcinogenesis $(14,36,37)$, but the tumor suppressive effects are lost in advanced stages of cancer. In the present study, we hypothesized that TGF- $\beta$ would first induce miR-143 expression and upregulation of miR-143 would in turn have a tumor suppressing function by inhibiting target genes (such as CD44, K-Ras, and Smad3). Reduced Smad3 expression could affect the TGF- $\beta$ pathway by downregulated expression of the Smad2/Smad3 complex. This complex will lose the effects on the transcription factor binding to the DNA promoter, including the pri-miR-143 promoter. TGF- $\beta$ binds to its receptor, which is activated and then recruits the Smad2 and Smad3 to form a complex, and in turn together with Smad4, translocates into the cell nucleus to promote gene transcription, including expression of the pri-miR-143/145 (Fig. 10). The pri-miR-143/145 is then cleaved to the mature miR-143. miR-143 downregulated its target gene CD44 and K-Ras function as a tumor suppressor gene. miR-143 also downregulates Smad3 expression, and the downregulated Smad3 restrains TGF- $\beta$. This is the miR-143-Smad3-TGF- $\beta$ pathway loop. The loop might explain why TGF- $\beta$ acts as a tumor suppressor in normal tissues, and in early carcinogenesis functions as an oncogene. TGF- $\beta$ induces the expression of miR-143 at first, and later the downregulated Smad3 represses miR-143 expression, enriching the miR-143 and TGF- $\beta$ pathway.

Our studies confirm that TGF- $\beta$ could induce expression of pri-miR-143/145, as miR-143 was frequently downregulated in NSCLC and lymph node metastases. Our studies demonstrate the biological functions of miR-143 in significantly inhibiting the migration and invasion of NSCLC cells. We also identified Smad3, CD44 and K-Ras as target genes possibly involved in miR-143-mediated migration and invasion suppression for lung cancer. Most importantly, we confirmed that TGF- $\beta$ induced the expression of miR-143, and later was repressed by the Smad3 target. In this way, miR-143 and Smad3 composed a circular loop for cancer. The miR-143 and TGF- $\beta$ pathway might provide a potential therapeutic strategy for NSCLC.

\section{Acknowledgements}

This study was supported in part by grants from Hunan Provincial Innovation Foundation For Postgraduates (CX2013B110), National Key Scientific \& Technology Support Program: Collaborative innovation of Clinical Research for chronic obstructive pulmonary disease and lung cancer (2013BAI09B09) and Science and Technology Department of Hunan Province Key Project (2014FJ2009). Most of the financial support was provided by C.H.M. 


\section{References}

1. Field JK, Oudkerk M, Pedersen JH and Duffy SW: Prospects for population screening and diagnosis of lung cancer. Lancet 382 : 732-741, 2013.

2. Curioni-Fontecedro A, Husmann L, Soldini D and Stahel RA: Primary non-small cell lung cancer response upon treatment with denosumab. Lung Cancer 82: 506-508, 2013.

3. Navarro A, Diaz T, Gallardo E, et al: Prognostic implications of miR-16 expression levels in resected non-small-cell lung cancer. J Surg Oncol 103: 411-415, 2011.

4. Vosa U, Vooder T, Kolde R, Vilo J, Metspalu A and Annilo T: Meta-analysis of microRNA expression in lung cancer. Int J Cancer 132: 2884-2893, 2013.

5. Yates LA, Norbury CJ and Gilbert RJ: The long and short of microRNA. Cell 153: 516-519, 2013.

6. Chitwood DH and Timmermans MC: Small RNAs are on the move. Nature 467: 415-419, 2010.

7. Lujambio A and Lowe SW: The microcosmos of cancer. Nature 482: 347-355, 2012.

8. Ebert MS and Sharp PA: Roles for microRNAs in conferring robustness to biological processes. Cell 149: 515-524, 2012.

9. Bartel DP: MicroRNAs: target recognition and regulatory functions. Cell 136: 215-233, 2009.

10. Bowen T, Jenkins RH and Fraser DJ: MicroRNAs, transforming growth factor beta-1, and tissue fibrosis. J Pathol 229: 274-285, 2013.

11. Luo Z, Dai Y, Zhang L, et al: miR-18a promotes malignant progression by impairing microRNA biogenesis in nasopharyngeal carcinoma. Carcinogenesis 34: 415-425, 2013.

12. Liu L, Yu X, Guo X, et al: miR-143 is downregulated in cervical cancer and promotes apoptosis and inhibits tumor formation by targeting Bcl-2. Mol Med Rep 5: 753-760, 2012.

13. Yoshida K, Saito T, Kamida A, et al: Transforming growth factor-beta transiently induces vimentin expression and invasive capacity in a canine mammary gland tumor cell line. Res Vet Sci 94: 539-541, 2013.

14. Dong L, Ge XY, Wang YX, et al: Transforming growth factorbeta and epithelial-mesenchymal transition are associated with pulmonary metastasis in adenoid cystic carcinoma. Oral Oncol 49: 1051-1058 2013.

15. Tian M, Neil JR and Schiemann WP: Transforming growth factor-beta and the hallmarks of cancer. Cell Signal 23: 951-962, 2011.

16. Choe C, Shin YS, Kim SH, et al: Tumor-stromal interactions with direct cell contacts enhance motility of non-small cell lung cancer cells through the hedgehog signaling pathway. Anticancer Res 33: 3715-3723, 2013.

17. Huang S, Holzel M, Knijnenburg T, et al: MED12 controls the response to multiple cancer drugs through regulation of TGF-beta receptor signaling. Cell 151: 937-950, 2012.

18. Argast GM, Krueger JS, Thomson S, et al: Inducible expression of TGFbeta, snail and Zeb1 recapitulates EMT in vitro and in vivo in a NSCLC model. Clin Exp Metastasis 28: 593-614, 2011.

19. Tai J, Xiao X, Huang ZG, et al: MicroRNAs regulate epithelialmesenchymal transition of supraglottic laryngeal cancer Zhonghua Er Bi Yan Hou Tou Jing Wai Ke Za Zhi 48: 499-503, 2013 (In Chinese).

20. Peng X, Guo W, Liu T, et al: Identification of miRs-143 and - 145 that is associated with bone metastasis of prostate cancer and involved in the regulation of EMT. PLoS One 6: e20341, 2011.
21. Boominathan L: The tumor suppressors $\mathrm{p} 53$, $\mathrm{p} 63$, and $\mathrm{p} 73$ are regulators of microRNA processing complex. PLoS One 5: e10615, 2010

22. Davis-Dusenbery BN, Chan MC, Reno KE, et al: Down-regulation of Kruppel-like factor-4 (KLF4) by microRNA-143/145 is critical for modulation of vascular smooth muscle cell phenotype by transforming growth factor-beta and bone morphogenetic protein 4. J Biol Chem 286: 28097-28110, 2011.

23. Wang YY, Ren T, Cai YY and He XY: MicroRNA let-7a inhibits the proliferation and invasion of nonsmall cell lung cancer cell line $95 \mathrm{D}$ by regulating K-Ras and HMGA2 gene expression. Cancer Biother Radiopharm 28: 131-137, 2013.

24. Shi L, Campbell G, Jones WD, et al: The MicroArray Quality Control (MAQC)-II study of common practices for the development and validation of microarray-based predictive models. Nat Biotechnol 28: 827-838, 2010.

25. Gordon KJ and Blobe GC: Role of transforming growth factorbeta superfamily signaling pathways in human disease. Biochim Biophys Acta 1782: 197-228, 2008

26. Blobe GC, Schiemann WP and Lodish HF: Role of transforming growth factor beta in human disease. N Engl J Med 342: 1350-1358, 2000.

27. Yanaihara N, Caplen N, Bowman E, et al: Unique microRNA molecular profiles in lung cancer diagnosis and prognosis. Cancer Cell 9: 189-198, 2006

28. Gao W, Yu Y, Cao H, et al: Deregulated expression of miR-21, miR-143 and miR-181a in non small cell lung cancer is related to clinicopathologic characteristics or patient prognosis. Biomed Pharmacother 64: 399-408, 2010.

29. Ma Q, Jiang Q, Pu Q, et al: MicroRNA-143 inhibits migration and invasion of human non-small-cell lung cancer and its relative mechanism. Int J Biol Sci 9: 680-692, 2013.

30. Hu Y, Ou Y, Wu K, Chen Y and Sun W: miR-143 inhibits the metastasis of pancreatic cancer and an associated signaling pathway. Tumour Biol 33: 1863-1870, 2012.

31. Liu H, Zhang SZ, Cai SR, Peng JP and Zheng S: Effect of microRNA143 expression on cell proliferation in colonic carcinoma. Zhonghua Zhong Liu Za Zhi 30: 498-501, 2008 (In Chinese).

32. Tabyaoui I, Tahiri-Jouti N, Serhier Z, et al: Immunohistochemical expression of CD44s in human neuroblastic tumors: Moroccan experience and highlights on current data. Diagn Pathol 8: 39, 2013.

33. Hiraga $\mathrm{T}$, Ito $\mathrm{S}$ and Nakamura $\mathrm{H}$ : Cancer stem-like cell marker CD44 promotes bone metastases by enhancing tumorigenicity, cell motility, and hyaluronan production. Cancer Res 73: 4112-4122, 2013

34. Raso-Barnett L, Banky B, Barbai T, Becsagh P, Timar J and Raso E: Demonstration of a melanoma-specific CD44 alternative splicing pattern that remains qualitatively stable, but shows quantitative changes during tumour progression. PLoS One 8: e53883, 2013.

35. Zeller E, Hammer K, Kirschnick $M$ and Braeuning A: Mechanisms of RAS/beta-catenin interactions. Arch Toxicol 87: 611-632, 2013.

36. Sawaki D and Suzuki T: Targeting transforming growth factorbeta signaling in aortopathies in Marfan syndrome. Circ J 77: $898-899,2013$.

37. Jakobsson $L$ and van Meeteren LA: Transforming growth factor beta family members in regulation of vascular function: in the light of vascular conditional knockouts. Exp Cell Res 319: 1264-1270, 2013. 